\title{
Tetralogy of Fallot with Absent Pulmonary Valve - A Case Report
}

\author{
${ }^{1}$ Md. Mazibur Rahman. \\ Department of Cardiac Surgery, Ibrahim Cardiac Hospital \& Research Institute, Shahbag, Dhaka.
}

\author{
Address for Correspondence: \\ Dr. Md. Mazibur Rahman., Junior Consultant, Department of Cardiac surgery \\ Ibrahim Cardiac Hospital \& Research Institute, Dhaka \\ e-mail : drmuzib2009@yahoo.com
}

\begin{abstract}
A 25 years male patient of Tetralogy of Fallot (TOF) with congenital absent of pulmonary valve (APV) presented with symptoms of palpitation and exertional respiratory distress without congestive heart failure. He underwent successful repair of intracardiac defects. The procedures consisted of patch closure of ventricular septal defect and right. ventricular outflow tract reconstruction with a monocusp transannular patch. Resection or plication of dilated pulmonary artery was not required. The patient is doing well without any symptoms.
\end{abstract}

Key wards: Tetralogy of Fallot, Absent pulmonary valve

\section{Introduction}

Tetralogy of Fallot (TOF) associated with absent pulmonary valve (APV) is a rare variant that comprises 2-6\% of all patients with Tetralogy of Fallot. ${ }^{1,2}$ In addition to the typical intracardiac abnormalities associated with Tetralogy of Fallot (Malalignment ventricular septal defect (VSD), stenosis of right ventricular outflow tract (RVOT), right ventricular hypertrophy (RVH) and overriding of aorta, patient with TOF / APV have rudimentary or absent pulmonary valve leaflets with severe pulmonary regurgitation (PR). Most importantly, neonates and infants presenting with TOF / APV commonly have characterstick aneurysmal dilatation of the pulmonary artery and its branches which can cause compression of the tracheobronchial tree expressing as a syndrome called absent pulmonary valve syndrome (APVS). ${ }^{3}$ Consequently TOF/ APV patients frequently require preoperative ventilatory support and often need early neonatal surgical repair ${ }^{4-6}$. Surgical treatment of neonates and infants with TOF/APV has been associated with increased post operative respiratory complications and hospital mortality. ${ }^{7-10}$

Several modifications of surgical technique have emphasized reducation of dilated pulmonary arteries, establishment of pulmonary valve competency using valve conduits and relief of obstruction of the tracheobronchial tree by means of suspension of the compressing pulmonary arteries, translocation of the pulmonary artery or even segmental resection of the lung ${ }^{10-13}$ The surgical modification noted above and recent advance in post operative care and ventillatory management of neonates and infants have all contributed to improve surgical outcomes in patients with. We report a successful repair of this rare anomaly in a young adult.

\section{Case Report}

A 25 years old Bangladeshi youngman was admitted at Ibrahim Cardiac Hospital \& Research Institute for elective surgery for TOF with APV having the past history of exersional respiratory distress and palpitation without heart failure. Auscultation revealed a systolic murmur associated with an early diastolic murmur alone the mid-left sternal border. The elctro-cardiogram showed right atrial hypertrophy (RAE), right ventricular hypertrophy (RVH) and complete right bundle branch block (RBBB). The chest roentgenogram demonstrated cardiomegaly with a cardiothoracic ratio of 60 $\%$ and pulmonary vascular marking were slightly increased with normal lung fields. Two dimensional echocardiography demonstrated valvular pulmonary stenosis with severe pulmonary regurgitation, large inlet septal VSD with mild aortic regurgitation $(\mathrm{AR})$;

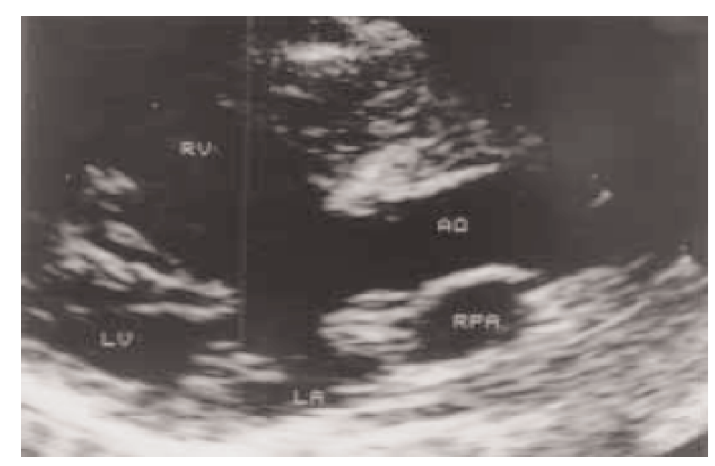

Fig.1.2-D echocardiogram.Parasternal

long-axis view demonstrating a large aortic root overriding a ventricular septal defect with an enlarged right pulmonary artery. 
a large aorta overriding the VSD (Fig.-1), cardiac catheterization and angiography confirmed the diagnosis of TOF with absent pulmonary valve and right. aortic arch. $90 \mathrm{~mm}$ of $\mathrm{Hg}$. systolic pressure gradient across the pulmonary valve annulus noted with pulmonary artery pressure of $26 / 14 \mathrm{~mm}$ of Hg recorded.

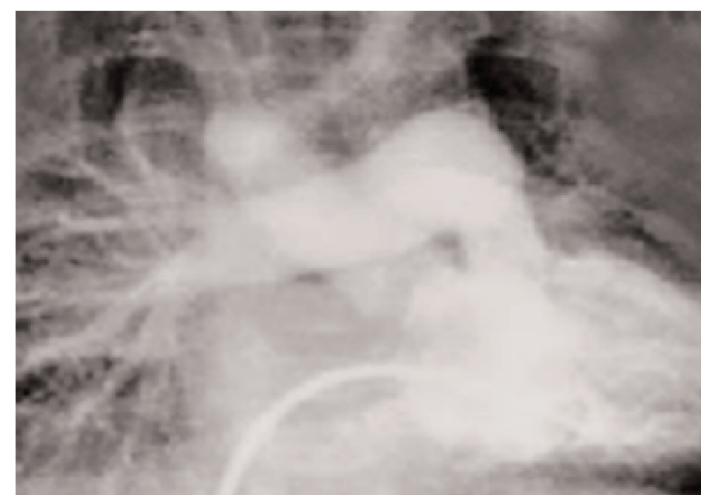

Fig.2. Anteroposterior view of right ventriculogram showing dilated right pulmonary artery and opacification of left ventricle and aorta through a ventricular septal defect.

A pulmonary arteriogram demonstrated dilated Rt. Pulmonary artery $(20 \mathrm{~mm})$, a distally displaced stenotic pulmonary valve annulus $(14 \mathrm{~mm})$ without pulmonary valve structure. A right ventriculogram demonstrated dilatation of right pulmonary artery (RPA) $20 \mathrm{~mm}$ (Fig.-2).

In June 2009, Corrective surgery through a median sternotomy was performed. The main pulmonary artery (MPA) was almost normal size but shorter in length and the pulmonary valve annulus was very narrow. Cardiopulmonary bypass was established with bicaval cannulation and the heart was arrested with antegrade cold blood cardioplegia, Right atriotomy (RA-tomy)was done. The pulmonary artery was longitudinally incised and the incision was extended to the right ventricular outflow tract. Vestigial remnants of the leaflets of the pulmonary valve were present in a small ventriculo-arterial junction.

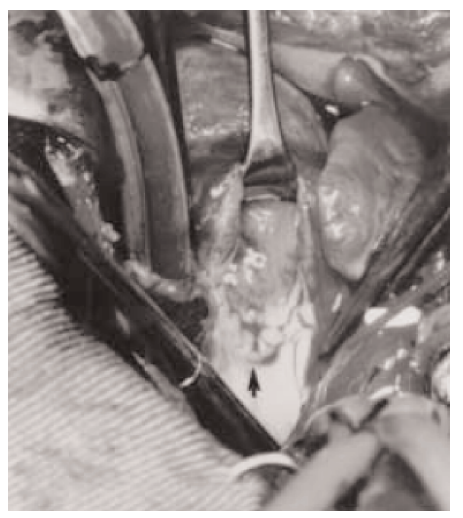

Fig.3. Intraoperative photograph demonstrating vestigial remnants of the leaflet of pulmonary valve (arrow)
Excision of septal and parietal bands were done at infundibulum. The VSD was closed using Dacron patch and right ventricular obstruction was relieved with insertion of pericardial monocusp transannular patch. The peak systolic pressure gradient across the right ventricular outflow tract (RVOT) came down to $32 \mathrm{mmHg}$ at the end of operation.. The post operative course was uneventful.

Follow up after 6 months by echocardiography revealed no residual left to right shunting at ventricular level, the peak systolic pressure gradient across the right ventricular outflow tract was $28 \mathrm{mmhg}$, moderate pulmonary regurgitation with mild tricuspid regurgitation. $\mathrm{He}$ is well without any symptoms following 6 months of repair.

\section{Discussion}

Congenital absence of pulmonary valve is rare isolatedly and is more often associated with various heart defects usually tetralogy of Fallot. ${ }^{14} \mathrm{~A}$ combination of TOF with APV is also rare. Symptoms of absent pulmonary valve vary from life threating respiratory obstruction by aneurysmally dilated pulmonary arteries or cardiac failure in a neonate to absence of symptoms in patients who may live unrestricted lives for many years.

The markedly symptomatic patients especially neonate or infant with pulmonary atelectasis and right ventricular failure needs aggressive medical treatment. ${ }^{3}$ Usually the surgical results in the newborn is poor. ${ }^{4}$ But if the medical treatment fails, should undergo a corrective operation involving insertion of a valve or valved conduit in the RVOT and partial resection, plication or both of the aneurysmal pulmonary arteries. ${ }^{3,15}$ In contrast, older infants, children and younger patients having minimal symptoms or asymptomatic, such in our young adult one, should undergo a corrective operation electively at the time of diagnosis. ${ }^{3}$ That is why we relieved the right ventricular outflow tract (RVOT) obstruction and pulmonary regurgitation with a pericardial monocusp transannular patch in absence of pulmonary hypertension in our patient. The insertion of a pulmonary valve prosthesis, and resection or plication of the dilated right pulmonary artery is not essential.

\section{References}

1. Alsoufi B, William WG, Hua Z, Cai S, Karamlou $\mathrm{T}$ et al. Surgical outcomes in treatment of patients with tetralogy of Fallot and absent pulmonary valve. Eur J Cardiothorac Surg 2007;31:354-59

2. Myung KP, Troxler RG. In: paediatric cardiology for practioners, $4^{\text {th }}$ edition, published byHarcourt India private limited, $27 \mathrm{M}$ block market, Greater kailash II, New Delhi 110048,p-200-02 
3. Satoshi H,Lionel M,Josephine B,Isabel J,George C et al.Ventricular and pulmonary artery volumes in patients with absent pulmonary valve :Factors affecting the natural course. Circulation 1983;67:183-90

4. Lakier JB, Stanger P, Heyman MA ,Hoffman JI, Rudolf AM Tetralogy of Fallot with absent pulmonary valve, natural history and haemodynamic considerations. Circulation 1974 50:167-75

5. Lev M,Eckner F. The pathologic anatomy of tetralogy of Fallot and its variations. Chest 1964;45:251-61

6. Macartney FJ,Miller GA. Congenital absence of pulmonary valve .Br Heart $J$ 1970; 32(4):483-90

7. Snir E,Leval MR, Elliot MJ,Stark j.Current surgical techniqueto repair Fallot's Tetralogy with absent pulmonary valve syndrome. Ann Thorac Surg1991;51(6):979-82

8. Watterson KG, Malm TK,Kart TR,Mee RB.Absent pulmonary valve syndrome: operation in infants with airway obstruction. Ann Thorac Surg1992;54(6):1116-19

9. McDonnell BE, Raff GW,Gaynor JW, Rychik j, Godinez RI et al.Outcome after repair of tetralogy of Fallot with absent pulmonary valve. Ann Thorac Surg 1999;67(5):1391-95
10. IIbawi MN, Idris FS, Wessel HU, Paul MH, DeLeon SY.Tetralogy of Fallot with absent pulmonary valve. Should valve insertion be part of intracardiac repair? J Thorac Cardiovasc Surg 1981;81(6):906-15

11. Hraska V. Repair of Tetralogy of Fallot with absent pulmonary valve using a new approach. Semin Thorac Cardiovasc Surg pediatr Card Surg Annu 2005;132-34

12. Kreutzer C, Schlichter A, Kreutzer G.Tetralogy of Fallot with absent pulmonary valve : a surgical repair. $J$ Thorac Cardiovasc Surg 1999;117(1):192-94

13. Conte S, Serraf RM,Godart F, Lacuar Gayet F,Petit J et al.Technique to repair tetralogy of Fallot with absent pulmonary valve. Ann Thorac Surg 1997;63(5):1489-91

14. Kikuchi S and Yokozawa M. Absent pulmonary valve associated tetralogy of Fallot and complete atrioventricular septal defect. Ann Thorac Cardiovasc Surg 2005;11(1):44-47

15. McCaughan BC, Danielson GK,Driscoll DZ, McGoonDC. Tetralogy of Fallot with absent pulmonary valve:early and late results of surgical treatment. J Thorac Cardiovasc Surg 1985;89:280-87 